\title{
Asylum seekers: self-referrals to a large psychiatric hospital
}

\author{
Nicola Gray and Emad Salib
}

\begin{abstract}
We reviewed, prospectively, all patients who presented themselves at the reception of a large psychiatric hospltal, which had no casualty department, to assess the extent and value of a long standing 'unofficial emergency service' that has been provided for decades. We found no evidence that the service was abused or that it led to unwarranted admissions. The service could provide a useful point of entry to mental heatth services for certain patients. The 'ad hoc' emergency service described here is hoping to become a recognised 'Emergency Clinic' in the reprovided service, after the closure of this 100 year old poychiatric institution in the very near future.
\end{abstract}

Out of hours psychiatric emergency services in England and Wales are mainly provided in accident and emergency (A\&E) departments, on hospital wards and by domiciliary visits (Johnson \& Thornicroft, 1995). Emergency psychiatric clinics have been described in several studies e.g. the Maudsley emergency clinic (Lim, 1983), in-patient reception at Withington Hospital, Manchester (Whittaker \& Appleby, 1995), the Royal Edinburgh Hospital emergency clinic (McKenzie \& McKie, 1993) and the emergency clinic in Southampton (Smithies, 1986). Meng Hooi Lim's large study of the Maudsley emergency clinic noted that the $42 \%$ of patients who self-referred tended to present mostly out of hours. These were more likely to be psychotic and require admissions. A rate of self-referral of $66 \%$ has been reported in another study (Whittaker \& Appleby, 1995) and they suggested that the available emergency facility may have been inappropriately used as a form of primary care.

Self-referrals were also found to be associated with young age, male gender, unemployment, poor social cohesion, problem drinking, a forensic history and mild levels of psychiatric disorder (McKenzie \& McKie, 1993). One patient in 10 of the self-referrals were felt to be appropriate referrals compared with $69 \%$ of general practitioner (GP) referrals. McPhillips \& Spence (1993) noted that although many patients presenting at an inner London emergency clinic may be bypassing primary care, the emergency clinic has a broad remit and should seek to facilitate crisis resolution and not solely confine itself to the assessment of mental disorder.

The aim of this study was to identify characteristics of patients presenting at Winwick Hospital reception and to assess whether allowing patients to self-refer led to unnecessary admissions.

\section{The study}

Winwick Hospital is one of the few remaining psychiatric 'asylums' in the country. Built in 1897. Winwick Hospital is due to close shortly. Once long corridors led to more than forty wards, which held up to 2270 patients; now less than 270 patients remain.

Although there is no casualty department and a notice at the front entrance to the hospital clearly states that there are no emergency facilities, it has been the practice, for as long as anyone can remember, for doctors to assess patients who present at reception. Many of these patients are self-referrals, though some are brought in by the police or referred by their GP, community psychiatric nurse (CPN) or social worker. Some self-refer despite having had no previous contact with mental health services and are therefore bypassing the usual filters to psychiatric services. The practice of assessing and often admitting self-referrals has never been officially recognised. Emergency presentation at the hospital reception has continued despite the availability of a major A\&E department and an active psychiatric assessment centre only three miles away.

A two-part questionnaire was devised, to be completed by receptionists and doctors, for all patients presenting at reception during a specified period in 1995. Information collected included: time and date of presentation; basic demographic data; method of presentation: past and present contact with mental health services: psychotic symptoms and assessment of risk; diagnosis (the major categories of ICD-10 were used with the addition of social problems); and outcome of assessment.

Those patients who self-referred and were then admitted were followed up using data from 
medical records, to look at length of stay and diagnosis.

\section{Findings}

Sixty-two patients were assessed between $\mathrm{Au}$ gust and November 1995. Fifty-three per cent (33) of these were self-referrals, $31 \%$ (19) were brought in by the police or a social worker and $13 \%(8)$ were referred by their GP. Most $(60 \%)$ of the assessments took place over the weekend. Twenty-six (42\%) of assessments occurred between 5.00 p.m. and 1.00 a.m. Seventy-one per cent of assessments occurring between the hours of 9.00 a.m. and 5.00 p.m. were self-referrals and this was the time self-referrals most commonly presented. Patients brought in by the police most commonly arrived between the hours of 1.00 a.m. to 9.00 a.m. Forty patients $(65 \%)$ who were assessed were male, $74 \%$ (46) were not employed and $82 \%$ (51) lived alone. Mean age was 32 years (s.d. 9) and ranged between 19 and 62 years. Fifty-three patients $(85 \%)$ were less than 40 years old.

The majority of patients assessed (84\%) had GPs and $88 \%$ (55) had had previous contact with mental health services. All the patients brought in by the police had a history of contact with the service. Fifty-nine per cent (37) of those assessed had some current contact with the services (e.g. an out-patient appointment had been arranged or they were being seen by a CPN). For selfpresenters $48 \%$ (16) had some present contact with psychiatric services.

Patients were asked whether they had contacted anyone within the past few days about the problem with which they were presenting; $61 \%$ (20) of self-referrals had been seen by their GP or in $\mathrm{A} \& \mathrm{E}$ department before presenting at reception and were probably seeking a second opinion. Eighteen (29\%) of patients were described as being aggressive or hostile by receptionists, $22 \%$ (14) of patients were aggressive or hostile to doctors and two patients were physically aggressive. Twelve patients $(20 \%)$ presented a risk to others and $40 \%$ (25) were suicidal. Eight patients $(25 \%)$ who presented themselves were described as actively psychotic. The provisional primary diagnosis is given in Table 1 .

Sixty-two per cent (38) of patients were admitted informally while $5 \%$ (3) were put on a section, $4 \%$ (2) left without seeing the medical officer while $29 \%$ (18) were assessed but did not require hospital admission. Time of presentation did not appear to affect admission rate. GP referrals were more likely to be admitted than those from other sources $(P<0.05)$. Female patients and those with an enduring mental illness appeared to be more frequently admitted than other groups of self-presenters $(P<0.05)$. For
Table 1. Provisional primary diagnosis

\begin{tabular}{lc}
\hline & $n=60(\%)$ \\
\hline Organic disorder & $1(2)$ \\
Alcohol/drugs & $17(28)$ \\
Schizophrenia & $7(12)$ \\
Mood disorder & $13(22)$ \\
Neurotic, stress-related and somatoform & $8(13)$ \\
disorders & $10(16)$ \\
Personality disorders & $4(7)$ \\
Social problems & \\
\hline
\end{tabular}

those self-presenters who were admitted, the average length of admission was 22 days (median 20 days).

Length of admission and diagnosis of these patients was not significantly different from other in-patients in Winwick Hospital, most of whom would have been admitted via a consultant.

\section{Comments}

The main limitation of this study is the small sample size, which reduces its statistical power. The definition of service abuse is a difficult one and may depend more on subjective experience and sleepless nights than on statistics. In this study there were patients who could be said to have abused the system; there were those who left before the doctor arrived or who left during the interview; there were those who presented despite having been told by their consultant that they would not be readmitted; and there were two who gave false addresses. However, there are those who self-referred, having already consulted their GP, who were admitted and who remained in hospital for several weeks' treatment. Although patients seen out of hours were not all actively psychotic (less than one in five), those who were admitted showed no evidence, similar to the reviewed studies, that the emergency service was abused or admissions were unwarranted. Before the study was carried out, it had been suggested that inexperienced senior house officers were admitting patients inappropriately in the middle of the night at great cost to the Trust. If this had been so, one would have expected self-referrals who were admitted to have had relatively short admissions - either discharging themselves or being discharged by their consultant shortly after their admission. This was not the case. There is a possibility, however, that some patients stayed on the ward probably longer than would have been justified. The relatively high admission rate of those who presented at Winwick reception, compared to most of the reviewed studies, may reflect the fact that beds were fairly plentiful in Winwick during the study period or it may be because Winwick 
does not serve an inner-city population. It was not felt that, in general, the service was abused or that it led to unwarranted admissions, but that it provided a useful point of entry to mental health services for certain patients. Patients continue to self-refer to Winwick Hospital, to be assessed and to be admitted when appropriate. Provision will now be made for this service to continue in the new in-patient unit. 'Self-presenting' late at night to a tired, inexperienced doctor is not the back door to the hospital and to free bed and breakfast. It is unlikely that vulnerable patients, 'asylum seekers', were sneaking in through the back door while their consultants slept!

\section{References}

JOHNSON, S. \& THORNICROFT, G. (1995) Emergency psychiatric services in England and Wales. British Medical Journal, 311, 287-288.
LIM. M. H. (1983) A psychiatric emergency clinic. Study of attendances over 6 months. British Joumal of Psychiatry. 148, 460-466.

McKente, D. M. \& MCKIE, J. (1993) Psychiatric emergency clinic attenders. What can we learn from them? Health Bulletin, 51, 67-71.

MCPHILLIPS, M. A. \& SPENCE, S. A. (1993) Emergency work at an inner London psychiatric hospital: a study of assessments made over six months. Psychiatric Bulletin. 17, 84-86.

SmItHIES, J. M. A. (1986) A psychiatric emergency clinic Psychiatric Bulletin. 10. 357-359.

WHITTAKER, J. F. \& APPLEBY, L. (1995) A psychiatric emergency walk-in clinic: a dangerous substitute for primary care? Psychiatric Bulletin. 19, 129-134.

*Nicola Gray, Senior House Officer in Psychiatry. and Emad Salib. Consultant Psychiatrist, Winwick Hospital, Warrington Community Health Care (NHS) Trust

*Correspondence: Dr N. Gray, 3 New Farm Barns, Spark Hall Close, Stretton, Warrington, Cheshire WA4 4NU



\section{Seminars in Practical Forensic Psychiatry}

\section{Edited by Derek Chiswick \& Rosemary Cope}

Seminars in Practical Forensic Psychiatry is a concise account of the specialty from a strongly practical perspective. It systematically describe the relationship between psychiatric disorders and offending, with detailed discussion of the criminal justice system, court proceedings, mental health legislation, dangerousness, prison psychiatry, and civil issues. There are boxes summarising key points, illustrative case examples, and sample court reports. It is up-to-date, with references to the Reed Report, the Clunis Inquiry, supervision registers and recent legislation. Career guidance and a chapter on ethical issues are included. This book will be invaluable for general psychiatrists and for trainees in forensic psychiatry, as well as those other health and social work professionals having contact with mentally disordered offenders, and those who are part of the criminal justice system. Price EI7.50, 359pp., 1995, ISBN 0902241788

Available from good bookshops and from the Publications Department, Royal College of Psychiatrists, 17 Belgrave Square, London SWIX 8PG (Tel. 0171 -235 235I, extension 146) 